\title{
A favor e contra o método: a tensão entre racionalismo e anarquismo epistemológico na controvérsia entre Big Bang e Estado Estacionário ${ }^{+1^{*}}$
}

\author{
Alexandre Bagdonas ${ }^{1}$ \\ Universidade Federal de Lavras \\ Lavras - Minas Gerais
}

\section{Resumo}

Dado o crescimento de visões ingênuas e críticas à ciência e sua autoridade, é natural que se questione as propostas educacionais que possam fomentar ainda mais um relativismo. Tendo em vista esse risco, com base em estudos sobre história da cosmologia na primeira metade do século $X X$, argumenta-se a pertinência de se incluir controvérsias sobre a natureza da ciência na educação científica. Para isso, são apresentadas e discutidas duas visões antagônicas de filósofos da ciência sobre a mudança das teorias científicas: o racionalismo crítico de Imre Lakatos e o anarquismo epistemológico de Paul Feyerabend. Elas foram empregadas para criar duas sínteses de obras sobre a história da cosmologia: primeiro uma reconstrução racional da história e em seguida uma história com maior espaço para a pluralidade de teorias, incluindo a presença de fatores usualmente considerados não racionais na ciência. Como conclusão, se propõe que este tipo de controvérsia tem potencial para evitar que continuem aumentando visões ingênuas sobre a ciência, tanto baseadas em uma confiança excessiva na autoridade de especialistas, quanto de uma radicalização da desconfiança de qualquer autoridade.

Palavras-chave: Cosmologia; Natureza da Ciência; Controvérsias; Relativismo; Racionalismo; História da Ciência.

\footnotetext{
${ }^{+}$For and against method: the tension between rationalism and epistemological anarquism in the Big Bang against Steady State controversy

* Recebido: maio de 2020. Aceito: agosto de 2020.

${ }^{1}$ E-mail: alexandre.bagdonas@ufla.br
} 


\begin{abstract}
With the growth of naive and critical views about science and its authority, it is natural to question educational proposals that may further promote relativism. In view of this risk, based on studies on the history of cosmology in the first half of the 20th century, it is argued that it is pertinent to include controversies about the nature of science in science education. For that, are presented and discussed two antagonistic views of philosophers of science about the change in scientific theories: the critical rationalism of Imre Lakatos and the epistemological anarchism of Paul Feyerabend. They were used to create two synthesis of the history of cosmology: first a rational reconstruction of history and then, a history with greater space for the plurality of theories, including the presence of factors currently considered irrational in science. In conclusion, it is argued that this type of controversy has the potential to prevent the growth of naive views about science, both based on excessive trust in the specialists' authority, as well as a radicalization of the distrust of any authority.
\end{abstract}

Keywords: Cosmology; Nature of Science; Controversies; Relativism; Rationalism; History of Science.

\title{
I. Introdução
}

É antigo o receio de que ao trazer para a educação básica aspectos da história da ciência com maior ênfase para dimensões sociais, culturais e políticas, corríamos o risco de fomentar o relativismo e o questionamento da autoridade da ciência. Um exemplo de artigo influente que gerou debates foi "A história deveria ser proibida para menores de idade?", escrito pelo historiador da ciência Stephen G. Brush (1974), que dialogou com as expectativas usuais dos professores de física, que gostariam que seus alunos vissem os cientistas como seres humanos, mas que respeitam os padrões de imparcialidade, rigor lógico e verificação experimental das hipóteses. Para evitar uma possível desvalorização da ciência por jovens cientistas que estudam história da ciência, Brush argumentou que a história deveria ser empregada para "neutralizar o dogmatismo dos textos didáticos e transmitir algum entendimento da ciência como uma atividade que não pode estar divorciada de considerações metafísicas ou estéticas" (BRUSH, 1974, p. 1171, tradução livre).

Tensões envolvendo o a problematização da autoridade da ciência por meio de estudos de história, filosofia e sociologia da ciência (HFSC) foram intensas no fim do século $\mathrm{XX}$, tanto no âmbito dos Science Studies quanto na comunidade de pesquisa em ensino de ciências. Filósofos, historiadores e sociólogos da ciência, psicólogos cognitivos e educadores contribuíram para uma avaliação crítica do construtivismo (MATHEWS, 1998). Uma das 
conclusões destes debates foi a necessidade de se recuperar visões moderadas do realismo e do racionalismo, de forma a evitar o relativismo radical nas aulas de ciências (ADÚRIZBRAVO, 2004). As visões extremas do construtivismo social foram consideradas inadequadas como referencial para a educação científica (SLEZAK, 1994; NOLA, 1997). Porém, por outro lado, defendeu-se que estudos sociais e culturais da ciência tem grande valor pedagógico (KRAGH, 1998; GRECA; FREIRE, 2004).

No início da década passada intensificaram-se as discussões entre pesquisadores de ensino de ciências sobre que visão de ciência devemos buscar promover na educação científica, tornando-se cada vez mais estudado o conceito de "natureza da ciência". Como se trata de um conceito elaborado por educadores, a partir de estudos de história, filosofia e sociologia da ciência, ou seja, estudos metacientíficos, ou "sobre as ciências", há diferentes definições de "natureza da ciência" e estas foram se alterando conforme eram debatidas pelos pesquisadores (HODSON, 2014; MARTINS, 2015; BAGDONAS, 2015; ROZENTALSKI, 2018).

Alguns autores, com maior influência de estudos sociais da ciência, definem "natureza da ciência" incorporando em sua definição aspectos sociais e relações entre ciência, tecnologia, cultura e sociedade (VASQUEZ et al., 2007). Já outros, como Norman Lederman $(1992,2007)$, propuseram que seria melhor distinguir o conceito de "investigação científica" do de "natureza da ciência", restringindo o último às bases epistemológicas da atividade científica (LEDERMAN, 2007, p. 835).

Educadores que defendem a educação CTSA (Ciência, Tecnologia, Sociedade e Ambiente) tendem a discordar de Lederman, considerando que "boa parte do conhecimento científico e, portanto, de considerações sobre seu status, validade e confiabilidade, estão intimamente ligadas ao design, condução e comunicação de atividades investigativas" (HODSON, 2014, p. 911).

Após décadas de estudos, ficou claro que são inadequadas, e devem ser problematizadas na formação de professores de ciências e na educação básica, as chamadas visões “empírico-indutivista”, “dogmática e fechada” (GIL PÉREZ et al., 2001), inspiradas por epistemologias mais próximas de um "positivismo" ingênuo, o que Chalmers (1993) caracterizou como o "senso comum da ciência". Por outro lado, posturas radicalmente relativistas, que desvalorizam a ciência a partir da problematização de sua autoridade, também foram criticadas por educadores por seus riscos ao serem levadas para o ensino de ciências. Por isso, a postura predominante entre pesquisadores de ensino de ciências interessados nas contribuições da epistemologia para a educação tem sido reconhecer o caráter dialético da natureza da ciência, adotando posturas moderadas entre positivismo ingênuo ou absolutismo epistemológico e relativismo radical (BAGDONAS; SILVA, 2013).

Apesar de diferenças em abordagens e definições de natureza da ciência, foi se constituindo a chamada "visão consensual da natureza da ciência", um consenso pragmático criado por pesquisadores do ensino de ciências que busca contornar as dificuldades e 
divergências existentes entre as visões sobre a ciência de filósofos, sociólogos e historiadores da ciência. Neste processo, que ocorreu na segunda metade do século XX, nota-se influência dos epistemólogos que se posicionaram contra o Positivismo Lógico, como Karl Popper, Gastón Bachelard, Thomas Kuhn e Imre Lakatos. Os aspectos considerados "inadequados" são predominantemente associados a visões empiristas, indutivistas e positivistas, que foram amplamente criticadas por esses autores (BAGDONAS; ZANETIC; GURGEL, 2014).

Quando os cientistas dizem que a Amazônia está sendo devastada, devemos ou não acreditar na ciência? E quando os cientistas dizem que o aquecimento global tem origem antropogênica? E quando os cientistas dizem que estamos comendo agrotóxicos demais? E quando os cientistas dizem que devemos tomar vacinas? E quando os cientistas dizem que manifestações pacíficas têm mais efeito do que violentas? A resposta, no nosso entendimento, para todas essas perguntas é que a população deve ser capaz de, ouvindo os especialistas, se posicionar criticamente para agir de maneira consciente. Para que isso possa acontecer é necessário que os cientistas estejam dispostos a dialogar com a sociedade a fim de construir pontes entre as diferentes culturas (LIMA; NASCIMENTO, 2019, p. 593).

Nota-se o crescimento de visões anticientíficas, como o terraplanismo, a contestação das vacinas, do aquecimento global e, desde 2019, uma planejada desvalorização da imagem das universidades públicas, até mesmo pelo próprio Ministério da Educação. A dicotomia ficção-realidade tem nos imposto desafios constantes:

Existiu um "kit gay"? As escolas e universidades estão tomadas por uma espécie de conspiração vermelha, homossexual e corrupta? Houve, em 1964, um golpe militar? Há em marcha uma conspiração judicial contra Lula e o PT? Estamos dominados por uma imprensa golpista e reacionária, ávida por derrotar os avanços sociais dos governos progressistas? Ou estamos dominados por uma imprensa golpista, ávida por pintar nossa bandeira de vermelho e acabar com a moralidade da família brasileira? (CROCHIK, 2019, p. 297)

Pós-verdade e fake news tiveram influência decisiva em processos eleitorais em diversos países, como EUA e Brasil, por exemplo. Não podemos mais acreditar somente em autoridades como fonte de legitimação, pois está claro que indivíduos, partidos políticos e grupos coletivos têm seus interesses específicos. Nem mesmo vídeos e fotos podem ser vistos como evidências de supostos fatos, já que com o avanço tecnológico torna-se possível fabricálos de modo a dar veracidade a qualquer ficção.

Como decorrência da crítica a visões absolutistas e dogmáticas de ciência, oriundas de um positivismo ingênuo que vê o mundo não como construção, permeada de elementos de ficções, mas como descobertas de fatos, o ensino de ciências tem sido influenciado nas últimas décadas por visões epistemológicas construtivistas, que criticam essa dicotomia entre fato e ficção. Historiadores, filósofos e sociólogos da ciência têm demonstrado que ficções, invenções, idealizações e a construção de modelos idealizados também estão presentes na 
prática científica (BAGDONAS, 2011; CROCHICK, 2019). As teorias científicas começam com enunciados que são como contos de fadas para crianças: "Imagine um mundo sem ar, plano e que a Terra não se move" (LÉVY-LEBLOND, 2001, p. 573). Estão repletas de elementos imaginativos, como a geometria euclidiana e experimentos mentais, além de aparatos experimentais que permitem imaginar e produzir fenômenos artificiais. Assim, LévyLeblond propõe que a ciência é como a poesia, "uma mentira que diz a verdade" (LÉVYLEBLOND, 2001, p. 573).

Por outro lado, essa ênfase na ciência como construção humana, marcada por influências sociais, culturais, estéticas, entre outras, pode levar a um questionamento radical da autoridade da ciência, por exemplo, ao se questionar teorias científicas com base em pseudociência, misticismo ou doutrinas religiosas. É comum que se responsabilize o pósmodernismo por subsidiar teoricamente tais movimentos (LIMA et al., 2019; CROCHIK, 2019), o que pode nos levar a pensar que em vez de abordar controvérsias com base em história e filosofia da ciência, agora seria mais adequado fortalecer a confiança na ciência a partir de um ensino mais tradicional, pautado em conteúdos, teorias e experimentos, enaltecendo a confiança que devemos ter na autoridade da ciência. Ao contrário, vamos argumentar que o melhor caminho para se evitar esse tipo de visão ingênua, é a inserção de discussões explícitas sobre controvérsias envolvendo a natureza da ciência, com base em estudos de HFSC.

Neste artigo, exploramos as potencialidades pedagógicas de controvérsias epistemológicas debatidas por dois filósofos da ciência: Imre Lakatos e Paul Feyerabend, confrontando-as com estudos sobre a história da cosmologia no século XX.

Inicialmente, na seção "A favor e contra o método", apresentamos um resumo das tensões entre o relativismo epistemológico de Feyerabend e o racionalismo crítico de Lakatos. Começamos apresentando "O triunfo do Big Bang como um processo racional", inspirado em Lakatos, e depois retomamos o mesmo episódio histórico inspirados pela visão de ciência de Feyerabend, analisando "Uma história da cosmologia do ponto de vista de teorias marginais". Em seguida, discutimos a questão de "Como a teoria do Big Bang triunfou sobre teorias rivais", contrapondo as visões sobre a ciência destes dois filósofos. Concluímos argumentando a importância de levar discussões controversas como estas para as aulas de ciências na educação básica, como forma de evitar o crescimento de visões ingênuas, tanto cientificistas quanto radicalmente anticientíficas.

\section{A favor e contra o método}

Imre Lakatos (1922-1974) nasceu em Debrecen, na Hungria em 1922, onde estudou filosofia, matemática e física. Após a invasão da URSS a seu país em 1956, mudou-se para a Inglaterra. Tornou-se professor da London School of Economics, onde trabalhava o renomado filósofo da ciência Karl Popper, que influenciou muito a constituição de sua epistemologia (LAKATOS, 1971; SILVEIRA, 1996), e onde conheceu Paul Feyerabend (1924-1994). 
Nascido em Viena, doutor em física e filosofia, Feyerabend também foi, no início de sua carreira, muito influenciado por Popper. Ele e Lakatos concordavam com sua crítica ao indutivismo e viram com simpatia o falsificacionismo popperiano. Posteriormente, Feyerabend ficaria conhecido como um dos mais famosos defensores do relativismo, distanciando-se radicalmente da visão racionalista de Popper. Seu livro mais famoso, Contra o Método (1975), mostra sua visão crítica tanto da obra de Popper, quanto do racionalismo crítico de Lakatos. Sua postura epistemológica ficou conhecida como "anarquismo epistemológico" ou "pluralismo metodológico" (FEYERABEND, 1975; REGNER, 1996).

No prefácio do livro Contra o método, ele conta que sua ideia era criar um debate com seu colega Imre Lakatos. Essa obra seria a primeira parte de um livro sobre o anarquismo epistemológico, em que Feyerabend atacaria a posição racionalista, enquanto Lakatos reformularia essa posição, para defendê-la.

Juntas, as duas partes deviam retratar nossos longos debates em torno desse temadebates que tiveram início em 1964, prosseguiram em cartas, aulas, chamadas telefônicas, artigos, até quase o último dia de vida de Imre, e se transformaram em parte de minha rotina diária. A origem do ensaio explica o seu estilo: trata-se de uma carta, longa e muito íntima, escrita para Imre e cada frase perversa que contém foi escrita antecipando frase ainda mais ferina de meu companheiro (FEYERABEND, 1975, p. 1).

Imre Lakatos morreu antes que sua resposta à provocação de Feyerabend pudesse ser publicada. Porém, a partir do conjunto de sua obra, pode-se imaginar o que ele teria escrito. Isso foi feito pelo filósofo Matteo Motterlini, que estudou as correspondências entre os dois amigos, assim como suas obras e escreveu o livro "A favor e contra o método" (LAKATOS, et al., 1999). Na introdução do livro, o editor Motterlini inventou um diálogo fictício entre Feyerabend e Lakatos, baseado tanto no livro Contra o método, quanto em palestras e outros textos produzidos por ambos, além de sua correspondência ${ }^{2}$ (BAGDONAS, 2015, p. 56).

Feyerabend inicia o diálogo condenando a tentativa de Lakatos de salvar os conceitos de "progresso" e "razão" nas ciências: "Você alega que existem normas que são tão flexíveis que deixam margem científica para progredir e, ao mesmo tempo, são substanciais o suficiente para permitir que a razão sobreviva" (FEYERABEND citado em LAKATOS et al., 1999, p. 7). Lakatos defende sua proposta como um aperfeiçoamento do racionalismo crítico de Popper, baseada em conjuntos de teorias denominados por ele de programas de pesquisa, que podem ser avaliados durante períodos longos quando comparados com programas rivais, a partir de critérios racionais. Um programa de pesquisa é progressivo se novas teorias fizerem previsões ousadas, e ainda mais se elas forem confirmadas. O programa de pesquisa é degenerativo quando é caracterizado por teorias fabricadas só para acomodar os fatos já

\footnotetext{
${ }^{2} \mathrm{~A}$ introdução do livro, que contém o diálogo fictício entre Lakatos e Feyerabend, está disponível em: $<$ http://www.cresa.eu/pubblicazione/for-and-against-method/>. Acesso em: abr. 2020.
} 
conhecidos, sem fazer novas previsões, ou sem que estas sejam corroboradas (LAKATOS, 1970, 1971).

Uma objeção interessante é apresentada por Feyerabend na forma de questão: quanto tempo é preciso esperar para se decidir se um programa de pesquisa é degenerativo ou progressivo? Quando um cientista decide continuar trabalhando em certo programa de pesquisa, mesmo que haja evidências experimentais sendo interpretadas como falseamentos desse programa e apoiando programas rivais, podemos considerar que sua postura é irracional? Em certo momento, um programa pode parecer degenerativo, mas após certo tempo pode-se descobrir que na verdade ele não deveria ser abandonado porque logo propiciaria muitos avanços (FEYERABEND, 1970, p. 215).

Lakatos se defende dizendo que sua proposta não é normativa, ele não pretende dizer aos cientistas o que eles devem fazer, apenas quer poder julgar os programas de pesquisa do passado. Feyerabend não aceita esse contra-argumento, dizendo que inevitavelmente essas regras metodológicas que se obtêm a partir do estudo da história da ciência serão interpretadas como um "código de honestidade intelectual", ou seja, prescrições a serem seguidas pelos cientistas. Caso contrário, os padrões metodológicos seriam meros ornamentos verbais, lembranças dos tempos felizes em que seria possível fazer parte de uma atividade complexa e tantas vezes catastrófica como a ciência, seguindo regras simples e "racionais". Assim, para Feyerabend, o racionalismo crítico de Lakatos seria uma versão disfarçada de sua própria epistemologia, o "anarquismo epistemológico", uma epistemologia crítica à tese de que a ciência progride de modo racional. Ou seja, no fundo ambos concordariam (Ibidem, p. 216). No diálogo, se referindo a Lakatos, Feyerabend argumenta:

Qual é o sentido de estabelecer regras que podem ser seguidas ou ignoradas indiferentemente? Você é como o autor de um livro de receitas que descreve a receita para fazer uma boa pizza e depois comenta: "É claro que não estou lhe dizendo o que fazer, mas faça o que fizer, mantenha um registro" (LAKATOS et al., 1999, p. 8)

Enquanto Lakatos defendia a existência de critérios racionais e objetivos para a escolha entre programas de pesquisa, Feyerabend se colocava como um "relativista cultural", dizendo que só existem critérios psicológicos e sociais. Criticava a diferenciação da ciência nos contextos da descoberta e da justificativa, pois esta divisão seria artificial e infrutífera (FEYERABEND, 1975, p. 207). Para ele, os defensores de uma visão única e coerente para a ciência costumam dizer: a ciência pode ser complexa, mas ainda é racional. Mas o que querem dizer por racional? Uma possibilidade válida é a tese nominalista, segundo a qual "racional" seria apenas um nome único dado para uma série de procedimentos diferentes.

A ideia de que a racionalidade seria um procedimento geral presente em todas as atividades científicas não se sustenta. Ou a racionalidade é definida de maneira muito estreita, classificando como irracional, por exemplo, as artes e boa parte das 
ciências, ou é definida de uma forma muito abrangente, classificando como racionais não só toda a ciência, mas também a corte amorosa, a comédia ou as lutas de cachorros (FEYERABEND, 1975, p. 329).

Lakatos não concorda, e diz que considera racional que um cientista assuma o risco de dedicar seu tempo a um programa de pesquisa que parece ser degenerativo. Mas que não se deve dar tanta liberdade para esse tipo de programa, como Feyerabend propõe em seu "anarquismo epistemológico", ao celebrar uma pluralidade de teorias concorrentes, um oceano de diferentes possibilidades. Para Lakatos, "os editores das publicações científicas deviam recusar-se a publicar os textos que em geral contêm quer reações solenes da sua posição, quer absorções da contra insurgência ou até de programas rivais por recurso a ajustamentos linguísticos ad hoc. As fundações de investigação deviam, também, recusar as suas verbas" nesses casos (LAKATOS, 1971, p. 39). Ao que Feyerabend responde:

\begin{abstract}
E aqui encontramos outro "caso estranho do Dr. Jekyll e do Sr. Hyde". Primeiro, você dá total controle à sua veia anárquica, sustentando que o único tipo de comportamento irracional consiste em negar o estado do programa em que está trabalhando. Então você pede que editores e sociedades recusem impressão e fundos! (LAKATOS et al., 1999, p. 9)
\end{abstract}

Para este artigo, a discordância mais importante entre Lakatos e Feyerabend se dá em relação a posição dos autores sobre a importância de fatores sociais, culturais, políticos na história da ciência. Em sua "metodologia dos programas de investigação" Lakatos propôs que as reconstruções racionais da história da ciência fossem complementadas por teorias externas empíricas, ou seja, baseadas em estudos da história da ciência, para explicar os fatores residuais não racionais. Como exemplos de casos históricos em que fatores irracionais foram importantes na história da ciência, ele cita o desaparecimento da genética mendeliana na Rússia soviética na década de 50 e o descrédito que atingiu certas escolas de pesquisa das diferenças raciais genéticas nos países anglo-saxônicos na década de 60 (LAKATOS, 1971, p.35).

Para ele por mais que a história da ciência seja sempre mais rica que a sua reconstrução racional, a história interna é primária, de forma que a história externa teria uma importância secundária. Os problemas mais importantes da história externa seriam definidos pela história interna:

Seja qual for o problema que o historiador da ciência pretende resolver, é-lhe necessário em primeiro lugar reconstruir a parte concernente do desenvolvimento do conhecimento científico objetivo, isto é a parte concernente da "história interna”. (...) o que para ele constitui a história interna depende da sua filosofia, quer ele esteja ou não ciente disso. (...)[A]o construir a história interna, o historiador será muito seletivo: omitirá tudo o que é irracional à luz da sua teoria da racionalidade. Mas esta seleção normativa ainda não permite uma reconstrução racional completamente livre. (...) A história interna não é simplesmente uma 
seleção de fatos metodologicamente interpretados: ela pode ser ocasionalmente a sua versão radicalmente melhorada (LAKATOS, 1971, p.41).

Segundo Steven Shapin, historiadores da ciência em geral não aceitaram o conceito de Lakatos de "reconstruir racionalmente" a história, preferindo abordagens que busquem entender a profundidade e complexidade da história "real". Na década de 1960, questão envolvendo influências sociais sobre a ciência era considerada muito importante para os jovens interessados em história da ciência. Os estudantes eram iniciados em seus estudos sobre história e sociologia das ciências aprendendo sobre essas duas tendências opostas e se esperava que se afiliassem ao "externalismo" ou ao "internalismo". Os artigos que revisavam a produção destas áreas obrigavam o uso dessas categorias como estruturas para exposição (SHAPIN, 1992, p.333).

Atualmente, a maioria dos historiadores da ciência considera que a tensão entre "externalismo" e "internalismo" foi superada, sendo um sinal de maturidade da pesquisa nesse campo o fato de que as referências a "interno e externo" são cada vez menos comuns. A partir da década de 1980 quem continuasse usando estes termos estaria se traindo, mostrando ser um iniciante, amador, alguém de fora da comunidade ou desatualizado (Ibidem, p.333).

Nesse sentido, consideramos que o mais adequado para se levar a história da cosmologia para a educação científica é um postura que integra aspectos internos e externos ${ }^{3}$. Muitos pesquisadores que defendem a inserção da cosmologia na educação básica têm adotado este tipo de abordagem ${ }^{4}$, empregando tanto histórias com enfoque mais internalista (NORTH, 1965; HARRISSON, 1981; BRUSH, 1993), quanto externalista (KRAGH, 1996).

Apesar disso, para fins didáticos adotamos aqui uma postura que em vez de apresentar somente uma boa história da cosmologia, com um equilíbrio entre aspectos internos e externos, vamos apresentar duas histórias radicalmente diferentes. Inspirados por esta tensão, vamos analisar o caso da história da cosmologia do século XX.

\section{O triunfo da teoria do Big Bang como um processo racional}

James Peebles, ganhador do prêmio Nobel da física em 2019 por seus trabalhos em cosmologia, promovendo o modelo padrão da cosmologia, defende que as medidas da radiação cósmica de fundo, feitas pelos satélites WMAP e Planck, assim como dos telescópios situados no Atacama e Polo Sul, além de outros instrumentos, mostram-se evidências impressionantemente detalhadas da estrutura e evolução do universo e, com outros testes cosmológicos, tornam a cosmologia do Big Bang (teoria relativística $\Lambda$ CDM com

\footnotetext{
${ }^{3}$ Para mais detalhes sobre história internalista e externalista no ensino de ciências, e discussões envolvendo a influência de fatores sociais na ciência, ver (BAGDONAS; ZANETIC; GURGEL, 2014) e (BAGDONAS, 2019).

${ }^{4}$ ARTHURY, 2010; BAGDONAS, 2011; AZEVEDO, 2011; SKOLIMOSKI, 2014; BAGDONAS, 2015; BAGDONAS; AZEVEDO, 2017; SEABRA, 2018; SILVA, 2020.
} 
constante cosmológica e matéria bariônica) uma das teorias mais convincentes quanto se é possível ser em se tratando de ciências naturais (PEEBLES, 2014).

Histórias da cosmologia com uma visão "presentista", comuns em obras escritas por cosmólogos e divulgadores de ciência, costumam apresentar a teoria do Big Bang como uma verdade quase incontestável. O universo estático seria um erro histórico, superado racionalmente pelas observações do desvio espectral das galáxias. Einstein aparece nesses livros como um dos criadores da cosmologia moderna, mas tem pouco destaque. $\mathrm{O}$ maior "herói” é Edwin Hubble (BAGDONAS; ZANETIC; GURGEL, 2017), que teria evidenciado o "grande erro" de Einstein com seu potente telescópio (BAGDONAS; ZANETIC; GURGEL, 2018).

Luiz Arthury (2010) defendeu a potencialidade pedagógica da história da cosmologia do século XX, tendo a epistemologia de Lakatos como referencial teórico. Apresentou uma versão mais cuidadosa da história do triunfo da cosmologia do Big Bang: como o sucesso de um programa de pesquisa progressivo.

Em sua visão, a introdução da constante cosmológica por Einstein, para manter o universo estático, seria uma modificação ad hoc, ou seja, uma mudança arbitrária. Para Lakatos, as teorias não são facilmente refutadas por observações que as desafiem:

Aqui temos uma ilustração de como opera o cinturão protetor, que evita ataques diretos à teoria. A introdução desta constante satisfaz a heurística negativa do programa ao manter as coisas como se deseja, impedindo que a teoria seja descartada prontamente. De uma maneira ou de outra, ainda que tenha sido uma hipótese ad hoc com o intuito de salvar uma ideologia, acabou sendo algo positivo à relatividade ao permitir a sobrevivência da teoria mesmo diante de elementos contraditórios (ARTHURY, 2010, p. 71).

Para Lakatos ajustes ad hoc só são aceitáveis quando posteriormente são avaliados como progressivos. Quando há um acúmulo de ajustes sem verificação, o programa de pesquisa passa a ser visto como regressivo. Com o tempo a comunidade científica teria sido racional: a modificação ad hoc de Einstein não foi bem recebida. A existência da constante cosmológica não foi testada, justificada ou explicada em pesquisas posteriores e o modelo de universo estático acabou sendo abandonado.

A aceitação dos modelos de universo em expansão relativísticos, estudados por Alexander Friedmann em 1922 e Georges Lemaître em 1927, se deu ao longo da década seguinte, quando os desvios espectrais para o vermelho das galáxias foram interpretados como evidência contra os modelos de universo estático. A constante cosmológica mostrou-se desnecessária e o próprio Einstein reconheceu a introdução dessa constante como um erro. Porém, em contradição com a boa parte dos livros e obras de divulgação de cosmologia, não é adequado dizer que "Hubble descobriu a expansão do universo em 1929". Antes de Hubble, Slipher (1917) já havia observado os desvios espectrais para o vermelho das nebulosas espirais e de Sitter (1917), Wirtz (1922), Silberstein (1924), Lundmark (1924), Lemaître 
(1927) e Robertson (1928) haviam investigado a relação redshift-distância como forma de explicar o chamado "efeito de Sitter". Pode-se até dizer que Hubble estendeu e reinterpretou o programa de pesquisa de Slipher (KRAGH, 1996). A criação da teoria do universo em expansão teve vários colaboradores, em um processo que durou alguns anos, envolvendo tanto aspectos teóricos quanto experimentais. A ideia do universo em expansão surgiu observacionalmente com Slipher em 1912, teoricamente em 1922 com Friedmann, mas só passou a ser aceita na comunidade científica na década de 1930, com a divulgação dos trabalhos de Lemaître publicados em 1927, processo em que Eddington teve papel preponderante, ao traduzir e republicar o artigo em inglês (BAGDONAS, et al., 2017).

Nos EUA, a partir de 1938, George Gamow e colaboradores defenderam este modelo cosmológico em expansão com base em novos estudos de física nuclear, evolução estelar e origem dos elementos químicos em um universo quente e denso, que passou a esfriar por causa da expansão (NORTH, 1965; KRAGH, 1996). Segundo a maior parte dos livros sobre cosmologia recentes, um grande mérito destes cientistas foi fazer uma previsão correta de um fenômeno então desconhecido, a radiação de fundo de micro-ondas com uma temperatura de $5 \mathrm{~K}$.

Nessa visão racionalista, a previsão correta desta temperatura foi decisiva para o sucesso da teoria do Big Bang. A teoria do Estado Estacionário, o principal programa de pesquisa rival proposto por Fred Hoyle, Thomas Gold e Hermann Bondi em 1948, tornou-se um programa de pesquisa degenerativo (ARTHURY, 2010, p. 74). Esta teoria, que já havia sido seriamente desafiada pelas observações da radioastronomia e quasares, tornou-se ainda mais marginalizada com a descoberta da radiação de fundo de micro-ondas. A maioria dos poucos cientistas que a haviam estudado parou de estudar cosmologia, atuando em outros campos da física e da astronomia (KRAGH, 1996).

Após 1965, jovens físicos e astrônomos passaram a desenvolver a teoria do Big Bang aprendendo, através de manuais didáticos, que esta teoria superou racionalmente as teorias rivais pela boa adequação às observações astronômicas:

Porque escolhemos o 'modelo padrão'? E como ele suplantou as outras teorias, inclusive a teoria do Estado Estacionário? $\dot{E}$ um tributo à objetividade da astrofisica moderna o fato de que esse consenso não tenha sido atingido por mudanças de preferências filosóficas ou pela influência de mandarins da astrofisica, mas sim pela pressão dos dados empíricos (WEINBERG, 1977, p. 17, tradução livre).

\section{A história da cosmologia do ponto de vista dos marginalizados}

Ao defender o pluralismo teórico e metodológico, Feyerabend enfatiza como algo desejável para a ciência a existência de teorias diferentes, que abordagens alternativas ao que é aceito pela maioria da comunidade científica sejam estimuladas e financiadas 
(FEYERABEND, 1970). Nessa seção vamos apresentar uma versão diferente da história da cosmologia, com atenção a diferentes interpretações possíveis para o desvio espectral das galáxias e a radiação de fundo de micro-ondas. Argumentamos que a previsão da temperatura do universo pelos adeptos da teoria do Big Bang não foi um processo tão simples e racional, conforme descreveram os autores citados na seção anterior.

Na década de 1930, Fritz Zwicky propôs uma das primeiras teorias de "luz cansada", em que fótons perdem energia em sua trajetória desde sua emissão pelas galáxias distantes até chegarem na Terra. Desde então, vários mecanismos para explicar essa perda de energia, tais como arrasto gravitacional, a interação fóton-fóton, o efeito Compton e o efeito Raman, foram estudados por cientistas como Oskar Klein, Finlay-Freundlich, Max Born, Louis de Broglie e Paul Marmet (NORTH, 1965; ASSIS et al., 2008; ROCHA, 2009).

Além das teorias de luz cansada, vários outros modelos cosmológicos alternativos têm sido investigados por um número relativamente pequeno de cientistas, que contam com muito menos recursos, tempo de observação em telescópios, enfrentando muito mais dificuldades para publicar seus resultados do que os adeptos do modelo padrão da cosmologia. Alguns deles são a teoria do Estado Quase Estacionário, de Hoyle, Narlikar e Burbidge; a cosmologia de plasma, estudada por Hannes Alfvén e Eric Lerner, além de variações do modelo padrão da cosmologia, como o Big Bang frio e variações das constantes fundamentais (KRAGH, 1996; ROCHA, 2009; LÓPEZ-CORREDORIA, 2014).

A previsão da temperatura correta da radiação cósmica de fundo é apresentada na maior parte dos livros de cosmologia como uma grande comprovação experimental da teoria do Big Bang. No entanto, também encontramos temperaturas de universo semelhantes, entre $2 \mathrm{~K}$ e $6 \mathrm{~K}$, "previstas" por autores que assumiam que o universo era estático, como o físico suíço Charles Guillaume (1861-1938) no século XIX, e Arthur Eddington, Erich Regner, Walther Nernst e Finlay-Freundlich na primeira metade do século XX (ASSIS; NEVES, 1995; NEVES, 2000).

Além disso, a previsão de Gamow, Alpher e Herman foi bastante confusa. Eles publicaram mais de uma dezena de artigos entre 1948 e 1965, com valores para a temperatura do universo entre 5 e $50 \mathrm{~K}$. Suas previsões foram praticamente ignoradas pela comunidade científica até 1965, quando Robert Dicke e James Peebles fizeram, independentemente, previsões semelhantes às de Gamow, Alpher e Herman, sem conhecê-las. Quando Penzias e Wilson descobriram a radiação de fundo de micro-ondas, publicaram um artigo citando a previsão de Dicke e Peebles (ASSIS; NEVES, 1995; KRAGH, 1996).

Gamow, Alpher e Herman se engajaram em uma disputa de prioridade com Dicke, acusando-o de esconder propositalmente a previsão que tinham feito anteriormente. Gamow escreveu para Penzias chamando a atenção para as "melhores previsões" de temperaturas próximas ao valor medido de 3K, feitas por Alpher e Herman em 1948, e por Gamow em 1953 (REINES, 1972, p. 35). 
Alpher e Herman fizeram o mesmo, contando suas versões desta história, atribuindo a confusão de valores da temperatura do universo a erros de Gamow (Ibidem, p. 6). Os valores previstos para a temperatura do universo nessa época eram dependentes de muitos fatores observacionais, como a densidade do universo, cujo valor era estimado com pouca precisão na década de 1950 (KRAGH, 1996, p. 119). Contudo, por mais que os valores de temperatura propostos por Gamow, Alpher e Herman fossem confusos, sua principal contribuição foi investigar a radiação em um universo relativístico em expansão quente e denso.

Vemos desse modo que, assim como a "descoberta" da expansão do universo (BAGDONAS et al., 2017), a previsão da temperatura da radiação de fundo de micro-ondas não se deu em um processo racional, simples e linear: ela foi confusa e envolveu disputas de prioridade entre diversos cientistas.

Segundo alguns dos críticos da hegemonia atual da cosmologia do Big Bang (ASSIS; NEVES, 1995; NEVES, 2000; ASSIS et al., 2008; LOPÉZ-CORREDORIA, 2014), esta não foi aceita pela maior parte de seus adeptos porque foram apresentadas as alternativas, mostrando os argumentos a partir dos quais eles fizeram a sua escolha, mas sim por uma espécie de doutrinação científica a partir da escrita de uma história da cosmologia triunfalista. Como o modelo padrão da cosmologia recebe muito mais verbas e atenção dos pesquisadores, ele é evidentemente mais desenvolvido que teorias alternativas. As dificuldades encontradas pelos defensores de teorias alternativas ao "modelo padrão" da cosmologia em divulgar suas teorias científicas foram lamentadas por diversos autores, que criticaram o predomínio de uma única visão sobre as demais.

Foi publicada em 2004, na revista New Scientist, uma carta aberta à comunidade científica internacional criticando as dificuldades enfrentadas pelos defensores de teorias cosmológicas alternativas ao pedir financiamento para realizar pesquisas e publicar artigos que forneçam evidências contrárias ao modelo dominante. A carta foi assinada inicialmente por 33 cientistas, sendo três deles brasileiros: André Koch Torres Assis (Unicamp), Marcos César Danhoni Neves (UEM) e Domingos S. L. Soares (UFMG). Entre os signatários originais estavam Hermann Bondi e Thomas Gold (autores da teoria do Estado Estacionário criada em conjunto com Fred Hoyle em 1948), Halton Arp, Jayant Narlikar, Eric Lerner e Paul Marmet. Posteriormente, cerca de 200 outros cientistas, e mais algumas centenas de pesquisadores independentes assinaram a carta que continua disponível para ser assinada na internet ${ }^{5}$.

No livro "Fatos e especulações na cosmologia", Jayant Narlikar e Geoffrey Burbidge escreveram uma anedota, que lhes teria sido contada pelo físico indiano Subrahmanyan Chandrasekhar (1910-1995):

\footnotetext{
${ }^{5}$ New Scientist, May 22, 2004. Disponível em: <http://www.cosmologystatement.org/>. Ver também Rocha 2009 , p. 83.
} 
Após a proposta para a construção do telescópio ter sido aprovada, uma entrevista coletiva à imprensa foi convocada e nela estavam presentes Hubble e Eddington. Um jornalista perguntou, dirigindo-se a ambos: "Senhores, o que vocês esperam encontrar com este telescópio?" Ao que os dois cientistas responderam (Hubble?): “- Se eu soubesse a resposta, não seria preciso construir esse instrumento". 6

Segundo Narlikar e Burbidge, atualmente Hubble e Eddington não conseguiriam tempo de observação em nenhum telescópio se fornecessem explicações tão vagas. A política atual de financiamento de pesquisa exige que o cientista já diga o que pretende concluir com seu trabalho, antes mesmo de realizar a pesquisa. Isso dificulta a descoberta de quaisquer resultados inesperados, que entrem em contradição com as teorias vigentes ${ }^{7}$.

Fred Hoyle já não estava mais vivo quando a carta foi publicada. Mas, um ano antes de sua morte, publicou o livro Uma abordagem diferente para a cosmologia (HOYLE; et al., 2001) em que defendia uma visão semelhante à difundida na carta. O livro foi escrito com dois novos parceiros, o físico inglês Geoffrey Burbidge (1925-2010) e o astrofísico indiano Jayant Narlikar (1938-), defendendo uma nova versão da teoria do Estado Estacionário, conhecida como teoria do "Estado Quase Estacionário". Segundo os autores, essa nova teoria explicaria inclusive os dados das flutuações da radiação de fundo de micro-ondas medidos pelo satélite COBE (idem, p. 197).

No prefácio do livro, eles trazem a discussão sobre as dificuldades para publicar seus artigos e obter tempo de observação nos telescópios, por serem defensores de teorias alternativas da cosmologia:

Com os sucessos observacionais da cosmologia nos últimos anos, ela passou a ser considerada "uma big science", que precisa de uma grande quantidade de verbas para se sustentar. Isso fez com que muitos cientistas se interessassem pela área, inclusive físicos teóricos sem conhecimentos astronômicos, ou da história da cosmologia. A disputa por grandes verbas acentua a influência das agências financiadoras sobre os objetos de pesquisa [....] um fato da vida que é bem conhecido pelos profissionais, mas que provavelmente ainda não foi bem digerido pelo mundo em geral, é o esforço e a propaganda necessários para utilizar um instrumento de medida como o Telescópio Espacial Hubble ou o satélite COBE. É preciso que antes que se construa o instrumento, se façam previsões extravagantes do que será encontrado. Não é surpreendente que quando eventualmente as observações

\footnotetext{
6 Tradução de Soares, Domingos. Coluna COSMOS, 27 de fevereiro de 2013. Disponível em: $<$ http://www.fisica.ufmg.br/ dsoares/cosmos/13/cosmos4.htm>. Acesso em: mai. 2020.

7 Domingos Soares, um dos signatários da carta publicada na New Scientist em 2004, contou em Cosmos a anedota de Narlikar e Burbidge. Ele também apresentou uma série de outros textos muito interessantes, quase sempre com um tom crítico aos adeptos do modelo padrão da cosmologia, como, por exemplo, $<$ http://www.fisica.ufmg.br/ dsoares/isnot/isnot.htm>. Acesso em: mai. 2020.
} 
são realizadas com sucesso, há esforços ainda maiores para mostrar que o que deveria ter sido observado foi de fato encontrado. [...] Não há espaço para a descoberta de fenômenos que ainda não eram esperados. Os poucos cientistas que se dedicam a este tipo de problema, nunca vão conseguir tempo de observação nos telescópios (HOYLE et al., 2001, p. viii).

O cosmólogo Marcelo Byrro Ribeiro e o filósofo da ciência Antonio Augusto Passos Videira, ambos brasileiros, discutiram a presença de uma postura dogmática entre os autores defensores do modelo padrão. Defenderam que o pluralismo teórico e a visão das teorias científicas como representação da natureza poderiam neutralizar as influências negativas desse dogmatismo (RIBEIRO; VIDEIRA, 2004, p. 519). Segundo esses autores, alguns cosmólogos contemporâneos parecem confundir o seu objeto de estudo, o universo, com as suas teorias, que são modelos de universo. Desta forma corre-se o risco de permitir a instauração de um alto grau de dogmatismo na comunidade científica, tornando natural a postura pouco crítica de não se levar a sério as propostas alternativas (Idem, p.523).

Tendo apresentado estas duas visões da história da cosmologia no século XX, vamos agora analisar os consensos e discordâncias, à guisa de conclusão.

\section{Como a teoria do Big Bang triunfou sobre seus rivais?}

A teoria do Big Bang foi aceita pela maior parte da comunidade científica a partir da segunda metade da década de 1960. Ao longo desta década, pesquisas envolvendo quasares, radioastronomia e principalmente a radiação cósmica de fundo levaram quase todos os físicos e astrônomos interessados nestes estudos a abandonarem teorias alternativas, como a teoria do Estado Estacionário (BRUSH, 1993; KRAGH, 1996). Porém, no campo da história da cosmologia, continuam sendo feitas investigações sobre como outros fatores não puramente empíricos podem ter sido relevantes para a consolidação da cosmologia como uma área respeitada (BAGDONAS; KOJEVNIKOV, no prelo).

Peter Susalla (2013) defendeu que o crescimento do número de cientistas pesquisando na área, a variedade de problemas de pesquisa disponíveis para os jovens, a criação de novas instituições de pesquisa e formas de treino, como escrita de livros didáticos, foram pelo menos tão influentes quanto desenvolvimentos conceituais para tornar a cosmologia uma área considerada científica. Ele analisou a criação de dois programas para o ensino e pesquisa sobre cosmologia nos EUA: 1. Uma abordagem observacional da cosmologia, desenvolvida principalmente por Allan Sandage, Richard Tolman e H. P. Robertson, no California Institute of Technology. 2. O Gravity Group, na Universidade de Princeton, onde Robert Dicke, David Wilkinson e P. J. E. Peebles atuaram, teve um papel importante nas pesquisas envolvendo a radiação de fundo de micro-ondas, que graças a eles passou a ser conhecida como "radiação cósmica de fundo". 
Alguns livros didáticos também foram bastante influentes na conversão de cientistas à abordagem ortodoxa da cosmologia. O prêmio Nobel Steven Weinberg, após ministrar uma série de cursos sobre relatividade geral e cosmologia, publicou o livro Gravitation and Cosmology (WEINBERG, 1972). James Peebles, um dos criadores do Gravity Group, publicou o livro Physical Cosmology, adotando uma abordagem mais "física" para a cosmologia, em contraposição à abordagem "astronômica" de Allan Sandage (PEEBLES, 1971).

Além de artigos publicados, discutindo racionalmente observações astronômicas e suas interpretações, outros fatores normalmente vistos como "externos" influenciaram o debate cosmológico e a aceitação da teoria do Big Bang após a Segunda Guerra Mundial. Tanto Gamow quanto Hoyle escreveram livros de divulgação científica, que foram bastante influentes neste período (BAGDONAS; KOJEVNIKOV, no prelo). Segundo Ralph Alpher e Robert Herman (2001, p. 119) o livro "Os três primeiros minutos" (WEINBERG, 1979) foi "uma contribuição significativa para a aceitação do modelo do Big Bang por muitos cientistas, apesar de ter sido pensado para uma audiência mais geral".

Os livros de divulgação científica costumam apresentar a população em geral somente ideias já razoavelmente bem estabelecidas na comunidade científica. Gamow não respeitou esta tradição e apresentou, muitas vezes pela primeira vez, ideias inovadoras em livros de divulgação. Uma delas foi a ideia de um universo quente e denso, hoje chamado de teoria do Big Bang, que apareceu pela primeira vez em suas publicações em 1938, na história Sr. Tompkins no país das maravilhas. Somente em 1946 esta ideia seria apresentada, com mais rigor, em artigos revistados por pareceristas, na revista Physical Review. Gamow usou em seus livros o humor como estratégia para enaltecer suas propostas e criticar teorias rivais. Sempre apresentava suas próprias reconstruções da história da cosmologia, destacando nelas seu próprio papel e salientando os problemas, tanto de teorias rivais como a de Hoyle e seus colaboradores britânicos, quanto de propostas diferentes para a origem dos elementos químicos dentre os adeptos de modelos em expansão, como a de seu colaborador indiano Subrahmanyan Chandrasekhar (BAGDONAS; KOJEVNIKOV, no prelo).

Os livros de popularização da cosmologia escritos por Gamow e Hoyle também influenciaram muitos autores a fazer pesquisa em cosmologia. Alan Sandage e Steven Weinberg, dois dos mais influentes defensores da teoria do Big Bang a partir da década de 1960, foram particularmente influenciados pelo livro Creation of the universe, de Gamow. Sandage disse ter lido este "maravilhoso livro de Gamow" cerca de 5 ou 6 vezes, o que foi essencial para ajudá-lo a entender os artigos de cosmologia que começou a estudar na década de 1950, quando decidiu se especializar em cosmologia observacional. Já Weinberg, além de ter lido os livros de Gamow, também foi influenciado pelo livro Cosmology, escrito por Hermann Bondi (1952).

Em 1998 Alan Lightman e Roberta Brawer entrevistaram cerca de 30 físicos e astrônomos que pesquisaram sobre cosmologia após 1950, perguntando quais livros sobre 
ciência leram quando crianças e como se tornaram interessados por esta área de pesquisa. Os livros de Gamow, Hoyle e Bondi, popularizando a controvérsia entre Big Bang e Estado Estacionário, foram citados pela maioria dos entrevistados. Outros livros influentes, principalmente entre os cientistas mais velhos e entre os britânicos, foram os livros publicados por Arthur Eddington e James Jeans (LIGHTMAN, 1990).

Portanto, vemos que a "descoberta" da radiação cósmica de fundo em 1965 não foi a causa da aceitação da teoria do Big Bang na comunidade científica. Este foi um processo complexo que se deu ao longo da década de 1960, envolvendo uma série de fatores, como a realização de debates em conferências sobre diversos aspectos da astronomia, principalmente quasares, origem dos elementos químicos, e radioastronomia, a consolidação de novos grupos de pesquisa, além da publicação e adoção de livros didáticos nas universidades e até mesmo pela influência inusitada de publicações sobre cosmologia em obras de divulgação científica, que influenciaram não só a população leiga, mas também os jovens cientistas interessados em estudar cosmologia.

\section{Considerações finais}

A intensidade crescente e influência de propagação de notícias falsas, incluindo as que tratam de avanços científicos em áreas de interesse da população em geral, como a conturbada relação entre ciência, religião e a criação do universo, é um desafio complexo, que vai exigir muito empenho e estudo dos professores de ciências nas próximas décadas.

O ensino de aspectos básicos da cosmologia é importante para que o cidadão comum possa compreender a divulgação científica contemporânea de modo crítico e reflexivo, evitando tanto uma confiança ingênua no poder das autoridades científicas em realizar descobertas de modo neutro e definitivo, quanto uma postura ingênua que iguala ciência, pseudociência, opiniões pessoais e propostas de charlatães com estudos alternativos desconectados da comunidade científica.

Há uma diferença profunda entre a disputa entre teorias científicas bem fundamentadas, como a que ocorreu entre Big Bang e Estado Estacionário, algo saudável e desejável tanto para Lakatos quanto para Feyerabend, e a defesa de "controvérsias" que igualam teorias, como a teoria do Big Bang e a evolução das espécies, a outras propostas não científicas. Uma visão ingênua infelizmente comum é a de que a teoria do Big Bang e a teoria da evolução das espécies seriam "somente teorias" e supostamente contrárias ao "criacionismo", e por isso nas escolas deveriam ser ensinados "os dois lados da controvérsia".

Para que os alunos saibam problematizar essas visões ingênuas, não é razoável exigir que todos devam entender, com rigor, certos conceitos físicos e matemáticos necessários para uma compreensão profunda do modelo cosmológico padrão, como os tensores da relatividade geral, utilizados nas equações de campo, o fator de escala nas equações de Friedmann, o desvio espectral para o vermelho das galáxias e a radiação de fundo de micro-ondas. De qualquer forma, mesmo que alguém compreendesse esses conceitos profundamente, ainda 
assim faltariam mais conhecimentos para que essa pessoa pudesse ter uma postura crítica e reflexiva em relação à forma como a cosmologia contemporânea tem sido divulgada. Para isso é preciso também entender mais sobre o processo de criação e avaliação das teorias, vendo os cientistas como seres humanos, inseridos em seu contexto sócio-histórico. Tendo em vista a riqueza das discussões que a história da cosmologia permite realizar, consideramos que a história presentista, encontrada em obras que só apresentam os triunfos do Big Bang rumo a sua aceitação hegemônica, mostra uma visão muito pobre sobre o processo de construção das teorias científicas (BAGDONAS, 2015).

A cosmologia é uma ciência especial e potencialmente problemática, porque questões filosóficas, ideológicas e às vezes até mesmo religiosas, não podem ser facilmente separadas das questões estritamente científicas. Defender o ensino de cosmologia contemporânea deixando de lado estas questões problemáticas é apresentar uma visão distorcida. Justamente por permitir a condução desse tipo de discussões, com uma abordagem histórico-filosófica, a cosmologia contemporânea deveria ter um papel proeminente na educação científica (KRAGH, 2011; BAGDONAS; SILVA, 2015).

\begin{abstract}
Os pesquisadores formulam hipóteses ou conjecturas que podem não ter qualquer fundamento, baseiam-se em analogias vagas, têm ideias preconcebidas ao fazerem suas observações e experimentos, constroem teorias provisórias ou mesmo contraditórias, defendem suas teorias com argumentos fracos ou até irracionais, discordam uns dos outros em quase tudo, lutam entre si para tentar impor suas ideias. As teorias cientificas vão sendo construídas por tentativa e erro, elas podem chegar a ser bem estruturadas e fundamentadas, mas jamais podem ser provadas. $O$ processo científico é extremamente complexo, não é lógico e não segue nenhuma fórmula infalivel. Há uma arte da pesquisa, que pode ser aprendida, mas não uma sequência de etapas que deve ser seguida sempre, como uma receita de bolo (MARTINS, 2006, p. xix).
\end{abstract}

Lakatos e, principalmente, Feyerabend concordariam com esta descrição da prática científica, feita pelo historiador da ciência Roberto Martins. Ambos defendiam que o estereótipo do cientista como um ser exclusivamente racional se distancia demais da prática científica.

Acreditamos que as reconstruções racionais da história da ciência, criadas com finalidade didática, devam também dar espaço para teorias alternativas, assim como para os erros cometidos pelos cosmólogos em suas investigações sobre o passado e futuro do universo.

Ao levar para a educação essa visão de ciência mais próxima da prática científica e menos racional e idealizada, há um risco de se induzir concepções ingênuas, como um relativismo radical ou desvalorização da ciência por ela não conduzir a verdades absolutas. No entanto, acreditamos que se essa visão for apresentada de modo adequado, 
problematizando essas possíveis distorções, a visão dos alunos sobre a ciência pode até mesmo se tornar mais frutífera.

Por mais que não seja da alçada de professores de ensino médio solucionar complexos debates epistemológicos envolvendo a racionalidade da ciência, ou argumentar solidamente contra alguma das teorias alternativas ao modelo padrão da cosmologia, acreditamos que sua formação deveria prepará-los para poderem apresentar estas controvérsias aos estudantes. Mesmo sem encontrar uma resposta definitiva para as dúvidas suscitadas pelas discussões, este tipo de debate é essencial para que estudantes exercitem a importante habilidade de raciocinar, questionando criticamente o que seus professores lhes ensinam.

No início da década passada, surgiram diversas críticas à chamada "visão consensual da natureza da ciência", em particular em relação a assunção dogmática de enunciados na forma de listas, que simplificam debates epistemológicos complexos e dão a ideia que exista uma visão de ciência correta e adequada, evitando abordar assuntos que envolvem controvérsias epistemológicas, como entre realismo e antirrealismo, ou racionalismo e relativismo. Como alternativa, foi proposto que controvérsias científicas envolvendo debates sobre HFSC no ensino podem levar a aprendizado mais profundo sobre as características da ciência, a partir do contato com questões que envolvem diferentes posições epistemológicas (MATHEWS, 2012; BAGDONAS; ZANETIC; GURGEL, 2014, BAGDONAS et al., 2017; NORONHA; BAGDONAS; GURGEL, 2018).

Martins (2015) argumentou que embora os enunciados simples e categóricos da "visão consensual da natureza da ciência" possam ser interessantes para professores, já que podem contribuir para a condução de discussões concretas e diretas sobre natureza da ciência, eles também podem causar certa confusão, inclusive com o risco de fomentar o relativismo ingênuo, especialmente quando apresentados de forma descontextualizada e sem aprofundamento. Como proposta para substituir as listas de princípios, sugeriu uma série de temas e questões que podem orientar o trabalho com HFSC em sala de aula.

Com a proliferação de visões críticas à ciência e propagação deliberadamente mal intencionada de notícias falsas, muitos têm a sensação de que não é a melhor hora para problematizar a ciência e sua autoridade. Seria hora de adotar a chamada "visão consensual da natureza da ciência" e defender a ciência como construção humana, mas que tem valor, enaltecendo suas potencialidades para melhorar a vida humana. Porém consideramos que para educadores preocupados com a formação de indivíduos críticos não é coerente a adoção dogmática de teorias metacientíficas, aceitando passivamente a autoridade de especialistas das áreas de história, filosofia e sociologia da ciência. Ao invés disso, este campo rico e complexo deveria ser visto como uma área dinâmica permeada por debates, que devem ser conduzidos constantemente na formação inicial e continuada de professores.

Muitas das questões mais relevantes para a educação científica atualmente envolvem aspectos controversos sobre a natureza da ciência. Dentre elas, estão relações entre ciência, 
tecnologia e sociedade, a neutralidade da ciência e as tensões envolvendo realismo e relativismo. Em vez de evitar estes aspectos não consensuais na educação básica, defendemos que a pesquisa em ensino de ciências deve contribuir com subsídios para que estas questões tão desafiadoras sejam abordadas na educação básica (BAGDONAS, 2015).

Pesquisadores interessados nas contribuições da história e filosofia da ciência continuam defendendo a importância do diálogo em uma educação problematizadora, voltada para preparar os estudantes para exercer um raciocínio crítico e reflexivo:

Toda sorte de discussões e questionamentos que nos façam refletir sobre o que é o conhecimento cientifico e como ele é produzido não devem ficar distantes da escola. Pois é justamente nestas discussões que se evidenciam as características do conhecimento científico, seus pressupostos e limitações. A escola é o ambiente mais propicio para que este diálogo ocorra, ensinando os cidadãos a resolverem seus dissensos por meio do diálogo e da tentativa de compreensão das razões apresentadas pelos demais. A escola e o professor têm o privilégio de ser este local onde acontece a promoção destas virtudes necessárias à cidadania, à socialização dos seres humanos, promovendo assim uma sociedade mais coesa, que busca resolver seus conflitos e dissensos por meio do diálogo, (...). Assim a pluralidade de ideias passa a ser entendida como uma dádiva para se resolver problemas, criar novos pontos de vista e consequentemente novos horizontes, e não como um problema que divide e afasta as pessoas (BAGDONAS; AZEVEDO, 2017, p. 272).

Se os desafios recentes nos levam a questionar se a problematização da autoridade da ciência não teria atingido um grau excessivo, ou se continua havendo dúvidas sobre o papel que a HFSC pode ter no ensino de ciências, ao mesmo tempo, estes desafios "nos impelem a retomar e ressignificar sua defesa. História, Filosofia e Sociologia da Ciência: mais do que nunca!” (MARTINS, 2019, p. 268). Nesse sentido, para que se possa promover uma visão mais crítica e madura sobre a autoridade da ciência é importante estudar casos controversos, reconhecendo as diferentes vertentes epistemológicas, como o racionalismo e o relativismo; diferentes ênfases historiográficas como o externalismo e o internalismo, podendo debater questões importantes e atuais como o quanto a ciência deve ser influenciada por questões sociais, em direção à possibilidade de formar indivíduos que saibam não só aprender com os erros cometidos ao longo da história e tenham respeito pelo saber acumulado ao longo das gerações anteriores, mas que também tenham preparo necessário para "questionar e problematizar esse saber, tendo em vista a necessidade de promover um diálogo inteligente com o mundo" (BAGDONAS, 2019, p. 211).

Precisamos da HFSC para evitar as visões dogmáticas de ciência que possibilitam e favorecem o surgimento de posturas ingênuas em relação a ela, inclusive as radicalmente críticas. São os que acreditam na ciência como um método preciso de obtenção de verdades a partir de experimentos os mais suscetíveis a ter sua confiança na ciência abalada quando alguma polêmica se instaura e o caráter complexo da ciência como construção humana se faz 
proeminente. Daí a necessidade de estudos que permitam a construções de visões não dicotômicas sobre a relação entre ficção e realidade.

\begin{abstract}
Ao contrário do que se poderia imaginar, a compreensão da Física (e das ciências da natureza de maneira geral) como cultura, ao demonstrar o enraizamento das verdades cientificas no contexto histórico, social, cultural, econômico e tecnológico em que são criadas e no qual fazem sentido, explicitando seu caráter relativo a esse contexto, longe de contribuir para uma completa arbitrariedade no julgamento de toda e qualquer afirmação, ao contrário, nos fornece elementos fundamentais para a compreensão das diferenças e assimetrias entre formas de conhecimento (CROCHIK, 2019, p. 315).
\end{abstract}

Por isso, a realização de discussões sobre aspectos controversos da ciência mostra-se cada vez mais importante na educação, contribuindo para que se conheça "a riqueza da construção do conhecimento científico e, ao mesmo tempo, se tenha consciência dos limites da autoridade científica", o que pode fornecer subsídios para que se "conteste de maneira sensata e equilibrada as afirmações emitidas por especialistas sobre que tipo de sociedade queremos no futuro" (BAGDONAS; ZANETIC; GURGEL, 2014, p. 257).

Com isso, as próximas gerações estariam preparadas para se engajar em diálogos construtivos na busca por formas de se evitar propagação de fake news sem uma confiança ingênua na autoridade da ciência, pensando que estas questões complexas podem ser resolvidas se uma autoridade adequada, isenta, for consultada. Por outro lado também temos que evitar um relativismo radical, a ideia de que a ciência não tem nenhuma autoridade e de que tudo é questionável. Há de se reconhecer a gravidade do problema, de que é preciso problematizar de modo crítico toda autoridade e conhecimento, inclusive a científica, mas que isso não significa negar sua importância na sociedade contemporânea e seu potencial para transformá-la.

\title{
Agradecimentos
}

Uma versão preliminar deste trabalho foi apresentada no III Encuentro de Filosofía e Historia de la Ciencia en el Cono Sur em junho de 2014. Este artigo é decorrente da pesquisa financiada pela FAPESP, processo 2011/07728-4. Agradeço os comentários e sugestões feitos por Osvaldo Pessoa Jr., Domingos Soares, João Caluzi e Gustavo Rocha durantes as bancas de qualificação de defesa de doutoramento, e principalmente a João Zanetic e Ivã Gurgel pelas orientações ao longo da pesquisa. Agradeço também aos colaboradores do projeto Universal do CNPQ "Educar para transformar" Wilson Elmer, Nathan Lima, Fábio Marineli, Guilherme Lima, Herman Schiffer e Nilva Sales por sua leitura crítica do manuscrito. 


\section{Referências}

ADÚRIZ-BRAVO, A. Methodology and politics: a proposal to teach the structuring ideas of the philosophy of science through the pendulum. Science \& Education, v. 13, n. 7-8, p. 717 $731,2004$.

ALPHER, R. HERMANN, R. Genesis of the Big Bang. Oxford: Oxford University Press, 2001.

ARTHURY, L. H. M. A Cosmologia Moderna à Luz dos Elementos da Epistemologia de Lakatos. 2010. 133f. Dissertação (Mestrado) - Curso de Pós-graduação em Educação Científica e Tecnológica, UFSC, Florianópolis, 2010.

ASSIS, A. K. T.; NEVES, M. C. D. History of the $2.7 \mathrm{~K}$ temperature prior to Penzias and Wilson. Apeiron, v. 3, n. 2, p. 79-87, 1995.

ASSIS, A. K. T.; NEVES, M. C. D.; SOARES, D. S. d. L. A cosmologia de Hubble: De um universo finito em expansão a um universo infinito no espaço e no tempo. In: NEVES, M. C. D.; SILVA, J. A. P. D. (Ed.). Evoluções e Revoluções: O Mundo em Transição. Maringá: Editora Massoni e LCV Edições, 2008. p. 199-221.

AZEVEDO, H. Competência comunicativa de futuros professores frente à diversidade religiosa na abordagem do Tema "origens do universo". 2011. Dissertação (Mestrado em Ensino de Física) - Faculdade de Ciências, Universidade Estadual Paulista.

BAGDONAS, A. Discutindo a natureza da ciência a partir de episódios da história da cosmologia. 2011. Dissertação (Mestrado em Ensino de Física) - Ensino de Ciências, Universidade de São Paulo, São Paulo.

BAGDONAS, A. Controvérsias envolvendo a natureza da ciência em sequências didáticas sobre cosmologia. 2015. Tese (Doutorado em Ensino de Física) - Ensino de Ciências, Universidade de São Paulo, São Paulo.

BAGDONAS, A. História da Física para o Ensino de Física como Cultura: Debates sobre a Neutralidade da Ciência no Período Entreguerras. In: MARTINS, A. F. P. (Org.). Física, Cultura e Ensino de Ciências. São Paulo: Livraria da Física, 2019. Cap. 8. p. 195-214.

BAGDONAS, A. Propostas para a educação científica com base em estudos de história da física na primeira metade do século XX em uma abordagem transnacional. Em construção, n. 7, 2020. 
BAGDONAS, Al.; KOJEVNIKOV, A. Funny origins of Big Bang Theory. Historical Studies of Natural Sciences, no prelo.

BAGDONAS, A.; SILVA, C. Controvérsias sobre a natureza da ciência na educação científica. In: SILVA, C.; PRESTES, M. A. (Org.). Aprendendo ciência e sobre sua natureza: abordagens históricas e filosóficas. 1ed. São Carlos: Tipografia, 2013. p. 209-218.

BAGDONAS, A.; SILVA, C. Enhancing teacherss' awareness about relations between science and religion. Science \& Education, v. 24, p. 1173-1199, 2015.

BAGDONAS, A.; AZEVEDO, H. O projeto de Lei "Escola sem Partido" e o ensino de ciências. Alexandria, v. 10, p. 259-277, 2017.

BAGDONAS, A.; ZANETIC, J.; GURGEL, I. Controvérsias sobre a natureza da ciência como enfoque curricular para o ensino de física: o ensino de história da cosmologia por meio de um jogo didático. Revista Brasileira de História da Ciência, v. 7, n. 2, p. 242-260, 2014.

BAGDONAS, A.; ZANETIC, J.; GURGEL, I. Quem descobriu a expansão do universo? Disputas de prioridade como forma de ensinar cosmologia com uso da história e filosofia da ciência. Revista Brasileira de Ensino de Física, v. 39, p. e2602, 2017.

BAGDONAS, A.; ZANETIC, J.; GURGEL, I. O maior erro de Einstein? Debatendo o papel dos erros na ciência através de um jogo didático sobre cosmologia. Caderno Brasileiro de Ensino de Física, v. 35, n. 1, p. 97-117, 2018.

BAGDONAS, A.; FABRÍCIO, V.; GURGEL, I.; NORONHA, A.; VELASQUEZ, F. A didactic game about cosmology designed to tackle controversies about science. In: PIETROCOlA, M.; GURGEL, I. (Org.). Crossing the Border of Traditional Science Curriculum: innovative teaching and learning in Science Basic Education. 1. ed. Boston: Sense Publishers, 2017. p. 163-179.

BRUSH, S. G. Should the history of science be rated X? Science, v. 183, n. 4130, p. 11641172, 1974.

BRUSH, S. G. Prediction and Theory Evaluation: Cosmic Microwaves and the Revival of the Big Bang. Perspectives on Science, v. 1, p. 565-602, 1993.

CHALMERS, A. O que é a ciência, afinal? São Paulo: Brasiliense, 1993. 
CROCHICK, L. A ficção criadora do real. In: MARTINS, A. F. P. (Org.). Física, Cultura e Ensino de Ciências. São Paulo: Livraria da Física, 2019. Cap. 8. p. 195-214.

FEYERABEND, P. K. Consolations for the specialist. In: LAKATOS, I.; MUSGRAVE, A. (Eds.). Criticism and the Growth of Knowledge. Cambridge: Cambridge University Press, 1970. [Tradução para o português: A crítica e o desenvolvimento do conhecimento. São Paulo: Cultrix, p. 197-230, 1979]

FEYERABEND, P. K. Against method: outline of an anarchistic theory of knowledge. Atlantic Highlands, NJ: Humanities Press, 1975. [Tradução para o português: Contra o método. Editora UNESP, 2007].

GIL-PÉREZ, D.; MONTORO, I. F.; ALÍS, J. C.; CACHAPUZ, A.; PRAIA, J. Para uma imagem não-deformada do trabalho científico. Ciência \& Educação, v. 7, n. 2, p. 125-153, 2001.

GRECA, I. M.; FREIRE JR., O. A "crítica forte" da ciência e implicações para a educação em ciências. Ciência \& Educação, v. 10, n. 3, p. 343-361, 2004.

HARRISON, E. R. Cosmology. The Science of the Universe. Cambridge: Cambridge University Press, 1981.

HODSON, D. Nature of Science in the Science Curriculum: Origin, Development, Implications and Shifting Emphases. In: MATTHEWS, M. R. (Ed.). International Handbook of Research in History, Philosophy and Science Teaching. Springer Netherlands, 2014. p. 911-970.

HOYLE, F.; BURBIDGE G.; NARLIKAR, J. A different approach to cosmology. Cambridge: Cambridge University Press, 2001.

KRAGH, H. Cosmology and Controversy: The historical development of two theories of the Universe. Princeton: Princeton University Press, 1996. 500p.

KRAGH, H. Social Constructivism, the Gospel of Science, and the Teaching of Physics. Science \& Education, v. 7, 231-243, 1998.

KRAGH, H. On modern cosmology and its place in science education. Science \& Education, v. 20, n. 3-4, p. 343-357, 2011. 
LAKATOS, I. Falsification and the Methodology of Scientific Research Programmes. In: LAKATOS, I.; MUSGRAVE, A. (Eds.). Criticism and the Growth of Knowledge, Cambridge: Cambridge University Press, 1970. [Tradução para o português: A crítica e o desenvolvimento do conhecimento. São Paulo: Cultrix, 1979. p.109-243.].

LAKATOS, I. History of science and its rational reconstructions. Springer Netherlands, 1971. [Tradução para o português: História da ciência e suas reconstruções racionais. Lisboa: Edições 70, 1978].

LAKATOS, I; FEYERABEND, P.; MOTTERLINI, M. For and against method: including Lakatos' lectures on scientific method and the Lakatos - Feyerabend correspondence. University of Chicago Press, 1999.

LEDERMAN, N Nature of science: past, present, and future. In: ABELL, S.; LEDERMAN, N. (Eds.). Handbook of research on science education. Mahwah, NJ: Lawrence Erlbaum Associates, 2007. p.831-880

LÉVY-LEBLOND, J.-M. Science’s fiction. Nature, v. 413, n. 6856, 2001.

LIGHTMAN, A. P.; BRAWER, R. Origins: the lives and worlds of modern cosmologists. Cambridge, Mass.: Harvard University Press, 1990.

LIMA, N. W.; NASCIMENTO, M. M. Nos becos da Episteme: Caminhos confluentes para uma contra colonização didática em meio à crise da verdade. Caderno Brasileiro de Ensino de Física, Florianópolis, v. 36, n. 3, p. 589-598, dez. 2019.

LIMA, N.; VAZATA, P.; MORAES, A.; OSTERMANN, F.; CAVALCANTI, C. Educação em Ciências nos Tempos de Pós-Verdade: Reflexões Metafísicas a partir dos Estudos das Ciências de Bruno Latour. Revista Brasileira de Pesquisa em Educação em Ciências, v. 19, 2019.

LOPEZ-CORREDOIRA, M. Non-standard Models and the Sociology of Cosmology. Studies in History and Philosophy of Science Part B. Studies in History and Philosophy of Modern Physics, v. 46, Part A, p. 86-96, 2014.

MARTINS, A. F. P. Natureza da Ciência no ensino de ciências: uma proposta baseada em “temas" e "questões". Caderno Brasileiro de Ensino de Física, v. 32, n. 3, p. 703-737, 2015. 
MARTINS, A. F. P. História, Filosofia e Sociologia da Ciência: mais do que nunca! In: MARTINS, A. F. P. (Org.). Física, Cultura e Ensino de Ciências. São Paulo: Livraria da Física, 2019. Cap. 8. p. 195-214.

MARTINS, R. de A. Introdução: a história das ciências e seus usos na educação. In: SILVA, C. C. (Org.) Estudos de história e filosofia das ciências: subsídios para aplicação no ensino. São Paulo: Editora Livraria da Física, 2006. p. 17-30.

MATTHEWS, M. (Ed.) Constructivism in science education: a philosophical examination. Dordrecht: Springer, 1988.

MATTHEWS, M. Changing the Focus: From Nature of Science (NOS) to Features of Science (FOS). In: KHINE, M. S. Advances in Nature of Science Research. Dordrecht: Springer, 2012.

NEVES, M. C. D. A questão controversa da cosmologia moderna: uma teoria e suas incongruências - parte 1. Caderno Catarinense de Ensino de Física, v. 17 n. 2, p. 189-204, 2000 .

NOLA, R. Constructivism in science and science education: a philosophical critique. Science \& education, v. 6, n. 1-2, p. 55-83, 1997.

NORONHA, A.; BAGDONAS, A.; GURGEL, I. Is the Electron Real? Who Discovered the Expanding Universe? Debating non Consensus Topics of Nature of Science in Science Classrooms. In: PRESTES, M. E. DE B.; SILVA, C. C. (Org.). Teaching Science with Context. 1. ed. Basel: Springer International Publishing, 2018. p. 99-112.

NORTH, J. D. Measure of the universe: a history of modern cosmology. New York: Dover, (edição de 1991), 1965.

PEEBLES, J. Physical Cosmology. Princeton, 1971.

PEEBLES, J. Discovery of the Hot Big Bang: What Happened in 1948. European Physics Journal H, v. 39, p. 205-223, 2014.

REINES, F. (Ed.). Cosmology, Fusion and Other Matters: George Gamow Memorial Volume. Boulder: Colorado Associated University Press, 1972. 
REGNER, A. C. K. P. Feyerabend e o pluralismo metodológico. Caderno Brasileiro de Ensino de Física, v. 13, n. 3, p. 231-247, jan. 1996.

RIBEIRO, M. B.; VIDEIRA, A. A. P Cosmologia e Pluralismo Teórico. Scientiae Studia, São Paulo, v. 2, n. 4, p. 519-535, 2004.

ROCHA, G. R. Controvérsias científicas: o caso do modelo padrão da cosmologia. Caderno de Física da UEFS, v. 07, n. 01 e 02, p. 65-85, 2009.

ROZENTALSKI, E. F. Indo além da Natureza da Ciência: o filosofar sobre a Química por meio da ética química. 2018. Tese (Doutorado em Ensino de Física) - Ensino de Ciências, Universidade de São Paulo, São Paulo.

SEABRA, M. E. Problematizando o estudo da cosmologia para a Educação Básica: Por que a noite é escura? 2018. Dissertação. (Mestrado Nacional Profissional em Ensino de Física) - Universidade Federal de Lavras, Lavras.

SHAPIN, S. Discipline and bounding: the history and sociology of science as seen through the externalism-internalism debate. History of science, v. 30, p. 333-369, 1992.

SILVA, R. R. M. A Cosmologia em revista: uma Ciência SuperInteressante? 2020. Dissertação (Mestrado em Educação) - Programa de Pós-Graduação em Educação, Universidade Federal do Triângulo Mineiro. Uberaba.

SILVEIRA, F. L. da. A metodologia dos programas de pesquisa: a epistemologia de Imre Lakatos. Caderno Brasileiro de Ensino de Física, v. 13, n. 3, p. 219-230, jan. 1996.

SKOLIMOSKI, K. Cosmologia na teoria e na prática: possibilidades e limitações no ensino. 2014. Dissertação (Mestrado em Ensino de Física) - Ensino de Ciências, Universidade de São Paulo, São Paulo.

SLEZAK, P. Sociology of scientific knowledge and scientific education: Part 1. Science \& Education, v. 3, p. 265-294, 1994.

SUSALLA, P. From Philosophy to 'Science:' A Cultural and Disciplinary History of Cosmology in the Twentieth Century. 2013. Thesis (Ph. D.) - The University of Wisconsin, Madison. 
VÁZQUEZ, Á.; MANASSERO, M. A.; ACEVEDO-DÍAZ, J. A.; ACEVEDO-ROMERO, P. Consensos sobre la naturaleza de la Ciencia: la comunidad tecnocientífica. Revista Electrónica de Enseñanza de Las Ciencias, v. 6, n. 2, p. 331-363, 2007.

WEINBERG, S. Gravitation and Cosmology. John Wiley: New York, 1972.

WEINBERG, S. The first three minutes. Bantam: New York, 1977. 